\title{
The network structure of multilevel water resources governance in Central America
}

\author{
Jacob Hileman $^{1}$ and Mark Lubell ${ }^{1}$
}

\begin{abstract}
The acceleration of changes in global water resource systems is exacerbating the ability of governance institutions to adapt, particularly in developing world regions. We highlight one of the key challenges to resilience in environmental governancecoordinating governance processes within and across multiple interacting geographic levels - and investigate structures of local, regional, and multilevel water governance networks using empirical data from Central America. We examined hypotheses of multilevel governance network structure and function using descriptive statistics and exponential random graph models, and found that closed and open network structures are more prevalent at the local and regional levels, respectively, and that cross-level ties impart smallworld structures upon the multilevel network. Small-world networks are theorized to provide joint benefits on cooperation, policy learning, and resource distribution, all of which are necessary for effective water resources governance.
\end{abstract}

Key Words: cooperation; environmental governance; multilevel governance; small-world networks; social learning

\section{INTRODUCTION}

We bring a canonical model from the network science literature to bear on questions of environmental governance processes in an empirical context. Using data from Central America, we analyze whether regional water policy actors restructure multilevel governance networks in ways that support cooperation, social learning, and resource distribution (Cash et al. 2006, Gupta and Pahl-Wostl 2013, Lubell 2013), and explore the hypothesis that regional actors facilitate the evolution of "small-world" networks (Watts and Strogatz 1998, Watts 1999). Small-world networks combine locally clustered structures that support cooperation with open structures that facilitate knowledge and resource sharing (Berardo and Scholz 2010, Lubell 2013). We use descriptive statistics and exponential random graph models (ERGMs) to examine differences in network structures at the local and regional levels, as well as for the combined multilevel governance network. We hypothesize that closed structures will be more prevalent at the local level, where cooperation facilitates the implementation of water management and development activities, while open structures will be more prevalent at the regional level, where knowledge sharing and resource distribution aid in the planning of development programs (Young 2006, Berardo and Scholz 2010). Cross-level ties between local and regional actors may preserve this balance of open and closed structures, and result in a network that displays small-world properties.

Our analysis contributes to the literatures on environmental governance networks (Carlsson and Sandström 2007, Bodin and Crona 2009), policy process theories that focus on polycentric governance in social-ecological systems (Ostrom 1990, Anderies et al. 2004, Olsson et al. 2006, Lubell 2013), and regional water resources development and management (Lebel et al. 2006, PahlWostl et al. 2007, Pietri et al. 2015). Research on governance networks is increasingly recognizing the importance of multilevel perspectives, especially as it relates to institutional fit in complex social-ecological systems (Robinson and Berkes 2011, Bodin et al. 2014, McAllister et al. 2015, Guerrero et al. 2015b, Bodin et al. 2016, Bodin 2017). While a few studies have explored the idea of small-world networks in an empirical context (Uzzi and Spiro 2005, Uzzi et al. 2007, Mani and Moody 2014), the idea has not been extensively applied in the broad empirical research on environmental governance networks (Sandström and Carlsson 2008, Lubell et al. 2012, Bodin et al. 2016). However, small-world networks provide a conceptual framework for understanding cross-level ties between regional and local actors as a "rewiring" of the network to span boundaries among locally clustered subgroups (Watts and Strogatz 1998).

Theories of the policy process that address polycentric governance identify social learning, cooperation, and resource distribution as key processes that contribute to resilience in socialecological systems (Folke et al. 2002, Olsson et al. 2004, Adger et al. 2005b, Berkes and Turner 2006, Lebel et al. 2006, Henry and Vollan 2014). Hence, instead of focusing on a single social process, we highlight how effective governance networks must simultaneously enable multiple social processes. Social learning describes the process of information sharing and processing among multiple actors (Pahl-Wostl et al. 2007, Henry 2017), and is necessary for adapting to the complexity inherent in water governance, where diverse policy actors interact in an uncertain and dynamic environment (Pahl-Wostl et al. 2007, Ostrom 2009). Cooperation is required when water problems create interdependence among resource users and other stakeholders, for example, in the case of common-pool resources like groundwater, or with public goods like water supply infrastructure (Ostrom 1990, Pretty and Ward 2001). These issues involve collective-action problems where resource users have an incentive to free-ride on the efforts of others. In this regard, small-world networks provide a combination of boundary spanning for social learning and closure for cooperation (Berardo and Scholz 2010).

Lastly, we address how regional policy actors might contribute to the resilience of water governance in Central America and other developing regions. Historically, water development programs have favored interventions at the local level, and have 
underemphasized the role of regional actors (Mohan and Stokke 2000, Barrett et al. 2001, Robinson and Berkes 2011, Dodman and Mitlin 2013). However, the increasing scale of global environmental issues has highlighted the interdependence among actors at the regional level, and stimulated the growth of multilevel and polycentric governance arrangements (Wyborn and Bixler 2013, McAllister et al. 2015, Berardo and Lubell 2016, Hamilton and Lubell 2017). In Central America and developing regions generally, regional water policy actors represent diverse groups, such as intergovernmental associations, transnational advocacy coalitions, and international nongovernmental organizations (Hileman et al. 2018). Regional governance networks have been demonstrated to help develop trust and shared norms (Wyborn and Bixler 2013), promote knowledge sharing (Pietri et al. 2015), facilitate access to financial and material resources (Lemos and Agrawal 2006, García-López 2013), and improve coordination across geographic and administrative boundaries (Berkes 2004, Nelson 2009, Ika and Donnelly 2017) among a wide array of local and regional actors.

\section{Background: regional water governance in Central America} Lemos and Agrawal (2006:298) define environmental governance as "the set of regulatory processes, mechanisms and organizations through which political actors influence environmental actions and outcomes." Water governance encompasses the universe of organizations and institutions involved in water resources development and management activities, including project planning and implementation, policy formulation, allocation of water rights, monitoring and evaluation, and enforcement of laws and norms of water use (Folke et al. 2005, Lemos and Agrawal 2006). Following the definitions of Gibson et al. (2000) and Cash et al. (2006), a water governance network is considered multilevel when it operates across different levels of a hierarchical dimension or scale, such as local and regional geographic territories. This concept of a multilevel network should not be confused with the narrow technical definition provided by Lomi et al. (2016) and Wang et al. (2013), which considers each level to be a unique class of nodes (e.g., scientists and research institutes) and focuses primarily on methods of network analysis.

Regional governance is emerging around the world as global phenomena like climate change, declining water quality and availability, and international trade increase the geographic scope of environmental problems (Vörösmarty et al. 2000, Taylor et al. 2013, Gleick and Ajami 2014) and highlight the transboundary interdependence among actors and ecosystems (Janssen et al. 2006, McAllister et al. 2015, Bodin et al. 2016). The impacts of these phenomena vary substantially across localities within a defined region, and regional governance institutions are more resilient when they promote cross-level learning, cooperation, and resource sharing (Folke et al. 2002, Adger et al. 2005a, 2005b, Cash et al. 2006, Berkes 2007, Pahl-Wostl et al. 2008, Pahl-Wostl 2015). The need for institutional capacity building and multilevel governance is especially acute in developing world regions, which are more vulnerable to pollution, climate change, weak enforcement, and other water resource challenges (Engle and Lemos 2010, Robinson and Berkes 2011, Ika and Donnelly 2017).

Central America is a particularly engaging empirical setting for studying multilevel governance, as international aid organizations there are increasingly recognizing regional governance as a complement to traditionally local-focused development programs (Davis et al. 2014). Like many developing regions, Central America features countries with a diverse set of socialecological contexts, limited administrative capacity, and a history of political conflict. Within this environment, regional water policy actors-groups like the Central American Regional Association for Water and the Environment, Regional Water and Sanitation Network, and Freshwater Action Network Central America-work to mobilize resources, facilitate knowledge sharing, and coordinate development strategies across diverse and physically distant local actors. As witnessed by one of the author's own participatory research in Central America, many donorfunded development programs are also restructuring their aims and functions around regional integration, including linking water management to broader goals of economic development and socio-political conflict management (Engle and Lemos 2010, Kuzdas and Wiek 2014, Hileman et al. 2016). The common thread among these groups is their focus on bridging between local actors across the region. However, in spite of this effort to strengthen regional governance, few empirical studies have examined the impacts this is having for an entire regional policy system.

The success of regional water governance institutions will ultimately be measured by their ability to improve biophysical and socio-political outcomes across localities throughout their defined regions. This is especially relevant in Central America, where the legacy of conflict, political instability, and poverty have generally hampered collaboration across countries and resulted in an emphasis on development at the subnational level (Kuzdas and Wiek 2014). While the water resource challenges facing communities in Belize, Costa Rica, El Salvador, Guatemala, Honduras, Nicaragua, and Panama vary substantially, without a regional focus the outcomes from individual development programs may fail to accumulate, which is a commonly observed problem in polycentric governance systems (Lubell 2013). This implies a need to balance between local and regional governance approaches through multilevel governance networks in order to provide the structures necessary for supporting local cooperation and regional knowledge and resource sharing (Guerrero et al. 2015a). These challenges are not unique to Central America, and the analysis presented here is potentially applicable to other developing regions. While the challenge of regional governance is also present in more developed countries, the presence of stronger political institutions and higher administrative capacity may provide advantages in establishing and sustaining new institutions and policy networks (Berardo and Lubell 2016).

\section{Theory: the small-world structure of multilevel governance networks}

Our theoretical argument focuses on how multilevel water governance networks may facilitate cooperation, social learning, and resource distribution. We define a water governance network as the set of relationships among the diverse public and private actors working to carry out water development and management activities in a defined geographic region (Lubell 2013). Research on governance and policy networks focuses on how structural properties of networks reflect underlying social processes (Carlsson and Sandström 2007, Bodin and Crona 2009, Henry and Vollan 2014). Empirical studies of polycentric governance systems, and in particular studies that draw on the Ecology of Games framework (Lubell 2013), illustrate how closed network structures (e.g., density, clustering) help facilitate cooperation, 
while open structures (e.g., centralization, short paths) may help facilitate knowledge sharing and resource distribution (Berardo and Scholz 2010, Lubell et al. 2014, McAllister et al. 2015, 2017). These theoretical ideas are based on the assumption that structural properties of networks provide the capacity for facilitating this suite of beneficial social processes. It is possible that less beneficial social processes could produce similar structural patterns (e.g., a set of core network actors maintaining a policy monopoly), but the structural analysis alone cannot distinguish these possibilities.

We argue that governance networks that possess small-world properties may provide joint benefits for cooperation and social learning. Small-world networks are one of the canonical models in the broad field of network science, which also includes ErdösRényi random graphs, preferential attachment, and others (Wasserman and Faust 1994, Barabási and Albert 1999, Newman et al. 2006, Jackson 2008). Mathematical models of small-world networks start with a highly clustered set of locally connected nodes, and then randomly "rewire" the connections among those nodes to span subgroups (Watts and Strogatz 1998, Newman and Watts 1999). The resulting structure is characterized by relatively high local clustering and short average path length (Milgram 1967, Watts 1999). Thus, small-world networks combine closed structures that support local cooperation with open structures that can more efficiently transmit information and resources across the entire network (Bodin et al. 2006, Bodin and Crona 2009, Berardo and Scholz 2010).

We argue that this small-world structure is found in multilevel governance networks, not governance at a single level alone. In the empirical setting here, closed structures at the local level may be indicative of local actors forming relationships to advocate for policies or foster collective action around project implementation in local communities - the "heavy lifting" of water development programs. At the regional level, more boundary-spanning and open structures may be indicative of regional actors building relationships to facilitate distribution of material resources and knowledge of best practices. Cross-level ties are formed when local actors collaborate with regional actors. These ties may be initiated, for example, by local actors seeking recognition from influential or resource-rich regional actors, or by regional actors acting to coordinate project implementation among local partners (Adger et al. 2005a, García-López 2013, Wyborn and Bixler 2013, Henry and Vollan 2014, Guerrero et al. 2015b). These cross-level ties are similar to the rewiring process in small-world network models, in that they reduce the overall average path length of the network while maintaining general patterns of local clustering.

In addition to cooperation and social learning, the presence of open and closed network structures may also influence who has the political power to control the distribution of resources and shape policy preferences and agendas (Bodin 2017, Morrison et al. 2017). Open structures can emerge due to the formation of centralized core actors, who possess a disproportionately high number of ties to other actors in the network (Barabási and Albert 1999). These actors may be well positioned to pursue their preferred policies (Bodin and Crona 2009), and in the case of regional policy actors, these objectives may or may not be consistent with locally defined management goals. On the other hand, closed structures, while important for cooperation within groups, may also reinforce an "us-and-them" mentality associated with competing advocacy coalitions in a policy system (Sabatier 1988, Bodin and Crona 2009). Resilient governance networks require constraining any negative effects of political power on the potential for cooperation and social learning (Lebel et al. 2006).

\section{Hypotheses of multilevel governance}

Using empirical data from Central America, we test hypotheses using a unique approach that compares networks constructed at the local and regional levels, and then combined into a multilevel governance network with the addition of cross-level ties. H1: The closed structure hypothesis holds that governance processes at the local level are driven by cooperation, and thus, the local network will possess more closed structures, as evidenced by higher levels of clustering. H2: The open structure hypothesis holds that governance processes at the regional level are driven by knowledge and resource sharing, and the regional network will possess more open structures, as evidenced by a higher degree centralization and shorter average path length. H3: The small-world structure hypothesis holds that the addition of cross-level ties effectively balances the closed and open structures found at the local and regional levels, and results in a network that displays small-world properties.

\section{RESEARCH DESIGN AND METHODS}

\section{Gathering multilevel governance network data}

We gathered the data for this study through an online search protocol and snowball sampling. We started by conducting a key word search, in English and Spanish, of contextual (e.g., water development, Integrated Water Resources Management) and geographical terms (e.g., Central America, Mesoamerica) to identify water governance actors that are active, though not necessarily with a physical presence, in Central America. For each set of search terms, we reviewed the first 50 results and recorded all unique actors. We then considered each actor's scope of work with regard to the boundaries of the network; actors were included only if they were actively working to support water development and management activities in Central America during at least part of the five years from 2010 through 2014.

Next, we examined the actors' websites for information about their activities and partners. Ties in the network represent collaboration between actors, and were established by recording the self-reported partners - not just hyperlinks - provided on each actor's organizational website. All ties are assumed to have the same weight, as it was not possible to determine strength of relationship from the website information. It was also not possible to determine the nature of collaboration, power, and influence, or other characteristics of the ties. We next expanded the population through multiple rounds of snowball sampling, which consisted of reviewing the websites of all the unique partners from each actor's ego-network. No new and relevant actors were discovered after four rounds of snowball sampling, and in all, we identified more than 2000 unique actors.

Lastly, we removed all actors that possessed only a single tie, often referred to as pendants, prior to analysis in order to focus on the core structures of the network (Hanneman and Riddle 2005), which also tend not to vary significantly across data collection methods (Yi and Scholz 2016). For actors without a website, or that did not report ties on their websites, this decision means that actors that did not contribute ties to the network are included 
only if they were named as partners by at least two other actors. After removing pendants, the multilevel water governance network for Central America comprises 624 unique actors. We provide analysis of the full network of 2000+ actors as supplementary material (Appendix 1) in order to illustrate how removing pendants does not alter the interpretation of the descriptive statistics and ERGM results.

In addition to network ties, we also used the website information to classify each actor's geographic scope of work as local (working within a single country) or regional (operating across multiple countries in Central America), and to determine the country where each actor's office is physically located. An actor's scope of work is not necessarily the same as physical location - it is possible for actors to be engaged in water governance activities (e.g., program funding, knowledge sharing) outside the countries where their offices are physically situated. We further recorded a dummy variable that indicated whether or not an actor reported partners on its website, where actors coded as zero did not self-report any partners. This dummy variable allowed us to control for actors that provided ties in the network when we estimated the ERGMs, which is important because organizations that report ties will necessarily have a higher average degree.

Constructing local, regional, and multilevel governance networks The multilevel water governance network for Central America consists of within-level and cross-level ties among local and regional actors (Fig. 1). The local level comprises actors whose scope of work is confined to the national or subnational level in Central America (e.g., Catholic Relief Services, El Salvador), while the regional level consists of actors who operate across multiple countries in Central America (e.g., Freshwater Action Network, Central America). This regional designation also includes global actors whose work encompasses, but extends beyond, Central America (e.g., Latin American Network of Water Centers, Global Water Initiative).

Fig. 1. Conceptual diagram of a multilevel governance network, including contextual examples of local (blue) and regional (red) water governance actors from Central America.

\section{Regional actors}

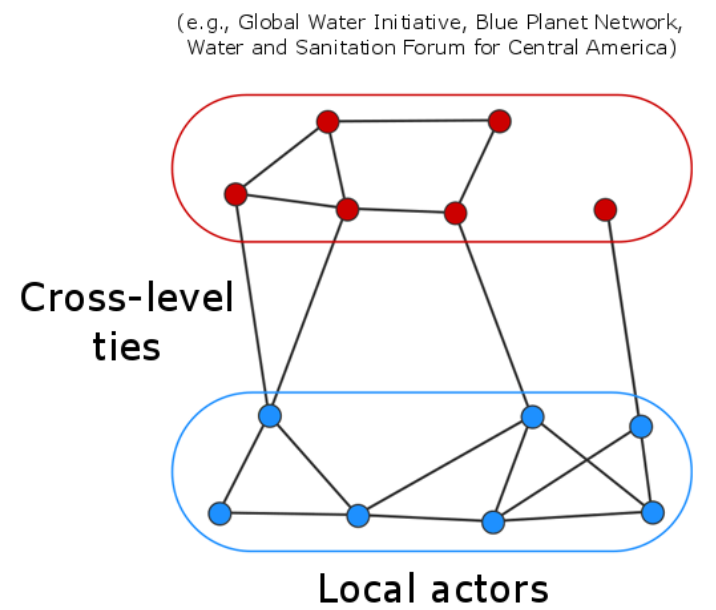

(e.g., Association of Water Committees of Honduras, National University of Costa Rica, Ministry of Environment and Natural Resources of Nicaragua)
In order to analyze the local and regional water governance networks independently, we first constructed the multilevel network (i.e., the network of ties among all 624 actors). We interpreted the data as an undirected one-mode network-we assume a tie between two actors represents a collaborative, reciprocal relationship - and we used the "scope of work" attribute to distinguish between local and regional actors (Fig. 2a). After building the multilevel network, we constructed undirected one-mode networks for both the local and regional levels (Fig. 2b and 2c, respectively) by isolating the local and regional actors, and their within-level ties. These last two networks explicitly ignore cross-level ties, and provide the basis for comparison necessary to measure the effects of regional policy actors on the structure of the full multilevel network.

\section{Analytical methods: descriptive network statistics and exponential random graph models}

To address our hypotheses, we used the "igraph" and "sna" packages (Csárdi and Nepusz 2006, Butts 2008) in the R Environment for Statistical Computing (R Development Core Team 2016) to calculate the following descriptive statistics for each of the three networks: density, average degree, degree centralization, average local clustering coefficient, average path length, and small-world quotient. Density is a general measure of connectivity, and represents the fraction of ties observed in a network with respect to the maximum number of possible ties. Average degree is also a measure of network connectivity, but unlike density, it is independent of the number of nodes in a network, and can be compared across networks of different sizes. The local clustering coefficient is a node-level measure that captures the fraction of a node's neighbors which are tied to one another, and the average value across all nodes provides a network-level measure of closure related to subgroup formation. Degree centralization is a measure of the extent to which a network is dominated by one or more high-degree nodes. Average path length is a measure of the mean number of links on the shortest path between any two nodes in a network.

The small-world quotient is a baseline comparison of observed network structure against the structure of a generalized random network with the same number of nodes and density, and provides a measure of the degree to which a network possesses small-world properties. The quotient represents a ratio of ratios - specifically, the ratio of observed and expected average local clustering coefficient divided by the ratio of observed and expected average path length - and the higher the value is above 1.0, the more smallworld the network. For a full explanation of the theoretical and mathematical formulation, see Watts (1999) and Davis et al. (2003).

Exponential random graph models allow us to explore the formation of network structures based on a set of hypothesized microlevel processes. The coefficients generated in an ERGM represent the change in the log-odds of tie formation, and indicate the directionality and magnitude of each process in the model. We used the "statnet" package (Handcock et al. 2008) in R to estimate ERGMs for each of the local, regional, and multilevel networks, and included terms in the models that capture the effects of social processes related to governance.

We used geometrically weighted edgewise shared partners (gwesp) to capture the general tendency for closure. We include 
Fig. 2. Networks analyzed in the study: (a) multilevel network of ties among local (blue) and regional (red) water governance actors in Central America, (b) network of within-level ties among local actors, and (c) network of within-level ties among regional actors. Nodes are sized by degree centrality, and isolates are removed from the local and regional network diagrams for improved visualization.
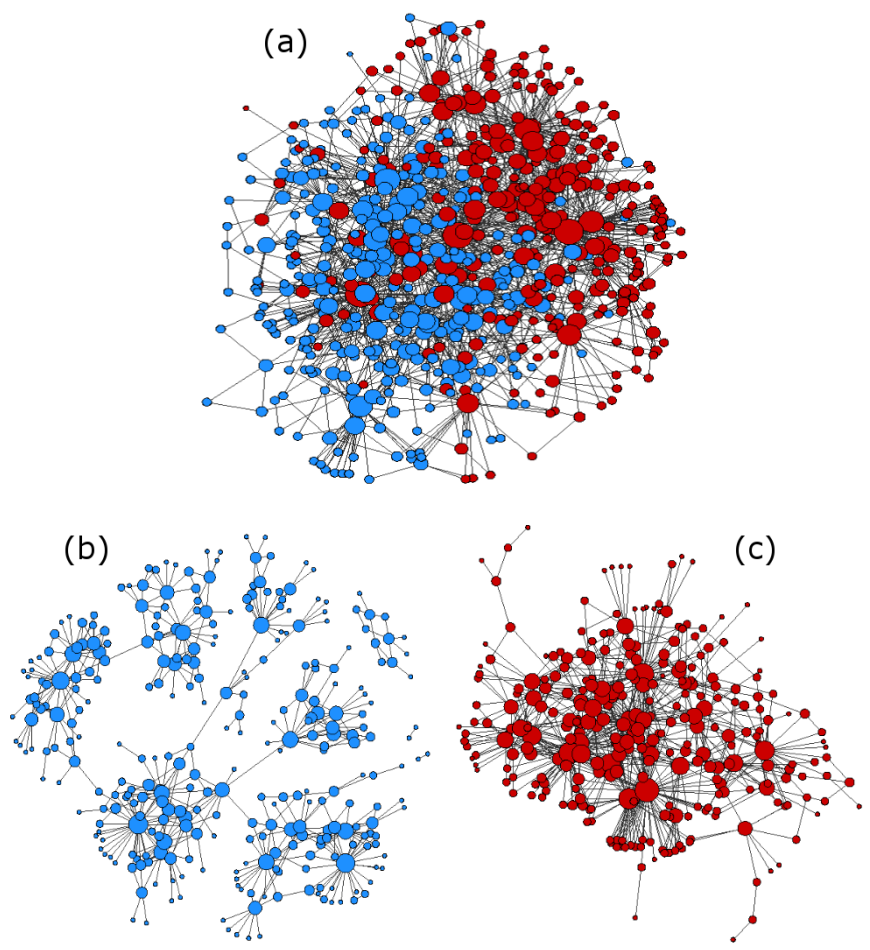

geometrically weighted degree distribution (gwdegree) to capture the propensity for more open, centralized network structures. The gwdegree term models the degree distribution in a network and may be thought of as a measure of antipreferential attachment; a positive coefficient indicates a relatively homogeneous degree distribution, while a negative coefficient indicates a more skewed or "fat-tailed" distribution where a few actors have a disproportionately high number of ties (Hunter 2007, Levy and Lubell 2017). From a purely structural perspective, a highly skewed degree distribution would be observed as a core-periphery structure if analyzed, for example, using the core-periphery formulation in UCINET (Borgatti and Everett 2000). Many network science papers are concerned with how such a skewed degree distribution could emerge, and one leading candidate is a process of "preferential attachment," whereby new ties in a network are more likely to attach to nodes with more existing ties (Barabási and Albert 1999). In a real social or political setting, it is also possible that a powerful core set of actors could control entry and selectively support the formation of particular network ties. However, the gwdegree term itself does not adjudicate between different types of network formation processes that could lead to a skewed degree distribution, and we note that teasing out specification in ERGM terms for open structures is an important goal for future research.

We include a dichotomous indicator variable using nodefactor to capture organizations that list partners on their websites, which is substantively important because they are more likely to be high- degree nodes that serve as hubs in centralized networks. As discussed earlier, many regional policy actors in Central America are explicitly seeking to build regional networks, and publicly listing partners on their websites is part of that strategy. We used nodematch to capture the effects of geographic level, including within-country homophily (i.e., ties among actors whose offices are in the same country) and within-level homophily (i.e., ties among actors operating at the same level in the multilevel network). We used nodefactor to capture the activity, or baseline rate of tie formation, for each country and geographic level. We also include edges to control for density, and a parameter for predicting isolates in the local and regional networks (the removal of pendant nodes precluded isolates in the multilevel network).

\section{RESULTS}

Descriptive statistics of multilevel governance network structures The descriptive statistics (Table 1) support our first two hypotheses of closed versus open structures, respectively, in local and regional governance networks. The local network exhibits a larger average local clustering coefficient, indicating relatively more closed structures, while the higher centralization and lower average path length in the regional network indicate a relatively higher proportion of open structures. Consistent with our third hypothesis, the multilevel network possesses a larger small-world quotient than either the local or regional governance networks. The balance between open and closed structures in the multilevel network is demonstrated by an average path length that is close 
Table 1. Descriptive network statistics for the local, regional, and multilevel governance networks.

\begin{tabular}{lccccccc}
\hline \hline Network & Nodes & Density & $\begin{array}{c}\text { Average } \\
\text { degree }\end{array}$ & $\begin{array}{c}\text { Degree } \\
\text { centralization }\end{array}$ & $\begin{array}{c}\text { Average local } \\
\text { clustering } \\
\text { coefficient }\end{array}$ & $\begin{array}{c}\text { Average } \\
\text { path length }\end{array}$ & $\begin{array}{c}\text { Small-world } \\
\text { quotient }\end{array}$ \\
\hline Local & 320 & 0.010 & 3.2 & 0.096 & 0.227 & 8.09 & 13.70 \\
Regional & 304 & 0.016 & 4.8 & 0.215 & 0.173 & 3.51 & 11.33 \\
Multilevel & 624 & 0.009 & 5.6 & 0.142 & 0.188 & 3.58 & 21.97 \\
\hline
\end{tabular}

to the value in the regional network, while the clustering coefficient remains higher relative to what would be expected from a random graph (a detailed breakdown of the small-world ratio calculation is provided in Appendix 2). Degree centralization is also higher than in the local network, further indicating more open structures in the multilevel network. Collectively, these findings suggest that the multilevel network balances structures that facilitate local cooperation with regional knowledge and resource sharing, and are consistent with the idea that cross-level ties in multilevel governance networks are akin to the rewiring process in small-world network models.

\section{Exponential random graph models of multilevel governance network structures}

The results for the ERGMs (Table 2) provide more depth to the descriptive statistics, and generally support our hypotheses of open and closed structures in multilevel governance networks. Each of the ERGMs converged and none were degenerate, and the goodness-of-fit indicates the models adequately capture the structures of the observed networks (Appendix 3).

The coefficient for shared partners is positive and significant in all three models, indicating a general force for closure at all levels of geographic scale. In addition, there is a substantial amount of within-country homophily in all three models, with the strongest effect at the local level. This indicates that closure occurs strongly among actors whose offices are located in the same country. The homophily effect is driven mainly by actors based in Central America; $81 \%$ of all homophilous ties occur between actors whose offices are found within the same country in Central America. Country-level homophily also contributes to the local network's large clustering coefficient, along with the country-level subgroups that are clearly visible in the network diagram (Fig. 2b).

The coefficients for antipreferential attachment are more difficult to interpret, in large part because they are highly dependent on the coefficient for the "reported ties" variable, which indicates organizations that report partners on their websites. The average degree of regional actors that reported ties is 16.2 versus 3.5 for those actors that did not report ties, while for local actors, the average degree is 8.7 versus 2.8 . As a result, regional actors that report partners on their websites are disproportionately likely to become central hubs in the regional and multilevel networks.

From a modeling standpoint, the inclusion of the reported ties variable appears to cause the antipreferential attachment coefficient to become strongly positive in the regional and multilevel networks. This contradicts our hypotheses about the relative abundance of open structures in the regional and multilevel networks, and is inconsistent with the descriptive statistics. It is important to reiterate that antipreferential attachment captures the endogenous variance in the degree distribution of the network, and taken on its own, will be negative for high-variance distributions (i.e., networks centralized around high-degree nodes), and positive for low-variance distributions. As we show in Appendix 1, the antipreferential attachment variable is highly negative in models without the reported ties variable. However, any exogenous statistic that represents highdegree nodes, such as the reported ties variable, will reduce the variance in the endogenous degree distribution captured by antipreferential attachment and increase the coefficient. We further note the standard errors for antipreferential attachment are higher in the full models in Table 2, which must also be considered when interpreting the coefficients.

Given the interaction between the antipreferential attachment and reported ties variables, and the increase in the standard errors, we tested for multicollinearity in the ERGMs using the methodology developed by Duxbury (2018) for calculating the variance inflation factor (VIF) of the model terms in an ERGM. While the results of the VIF assessment do not indicate extreme levels of collinearity in the models (see Appendix 4), the analysis suggests that the VIF is approaching a problematic level for the antipreferential attachment term in the local network ERGM (and is most problematic for the within-country homophily term). Even a small degree of collinearity may increase the standard errors of the coefficients with higher VIF, and possibly affect estimates for other variables in the model. Hence, the coefficient estimates for antipreferential attachment should be interpreted with caution, and the overall support for our hypotheses must be considered in light of both the descriptive statistics and ERGM results. This methodological complication is symptomatic of ERGMs that include many statistics derived from the same observed set of relational data, which are hypothesized to provide indirect evidence of underlying microlevel social processes.

The ERGM results have a theoretical and substantive interpretation relative to our hypotheses, as well as methodological implications. From the standpoint of theory and substance, the regional and local organizations that report ties are actively seeking to build boundary-spanning networks. For example, the website of the Blue Harvest program states, "Activities are designed to generate impacts beyond specific locations/projects in order to influence policies, governance, and practices at national, regional, and international levels." The data reflect the boundary-spanning activities of regional actors-out of the 1999 ties observed in the network, only 493 are cross-level ties-but regional actors contribute nearly two-thirds $(63 \%)$ of these cross-level ties. Hence, regional actors who report ties on their websites are contributing more cross-level ties, while also 
Table 2. Exponential random graph models (ERGMs) for the local, regional, and multilevel governance networks.

\begin{tabular}{|c|c|c|c|}
\hline & Local network & Regional network & Multilevel network \\
\hline \multicolumn{4}{|l|}{ Network processes: } \\
\hline shared partners ${ }^{\dagger}$ & $0.368^{* * *}$ & $0.511^{* * *}$ & $0.722 * * *$ \\
\hline & $(0.075)$ & $(0.059)$ & $(0.039)$ \\
\hline antipreferential attachment ${ }^{\dagger}$ & $-2.217^{*}$ & $1.663^{*}$ & $7.535^{* * *}$ \\
\hline & $(0.874)$ & $(0.772)$ & $(0.769)$ \\
\hline \multicolumn{4}{|l|}{ Geographic scale: } \\
\hline within-level homophily & & & $\begin{array}{l}0.487 * * * \\
(0.053)\end{array}$ \\
\hline within-country homophily & $\begin{array}{l}5.812^{* * *} \\
(0.386)\end{array}$ & $1.166^{* * *}(0.091)$ & $2.027 * * *(0.052)$ \\
\hline \multicolumn{4}{|l|}{ Baseline rates: } \\
\hline level activity: local & & & $\begin{array}{l}-0.528^{* * * *} \\
(0.048)\end{array}$ \\
\hline \multicolumn{4}{|l|}{ Country activity: } \\
\hline Costa Rica & $\begin{array}{l}-0.544 * * * \\
(0.163)\end{array}$ & $\begin{array}{l}-0.295^{* *} \\
(0.093)\end{array}$ & $\begin{array}{l}-0.027 \\
(0.054)\end{array}$ \\
\hline El Salvador & $\begin{array}{l}-0.674 * * * \\
(0.161)\end{array}$ & $\begin{array}{l}-0.544 * * * \\
(0.154)\end{array}$ & $\begin{array}{l}-0.010 \\
(0.056)\end{array}$ \\
\hline Guatemala & $\begin{array}{l}-0.537 * * \\
(0.164)\end{array}$ & $\begin{array}{l}-2.341 * * * \\
(0.672)\end{array}$ & $\begin{array}{l}-0.020 \\
(0.069)\end{array}$ \\
\hline Honduras & $\begin{array}{l}-0.673 * * * \\
(0.162)\end{array}$ & $\begin{array}{l}-0.794 * \\
(0.336)\end{array}$ & $\begin{array}{l}-0.041 \\
(0.064)\end{array}$ \\
\hline Nicaragua & $\begin{array}{l}-0.641 * * * \\
(0.166)\end{array}$ & $\begin{array}{l}-1.056^{* * *} \\
(0.307)\end{array}$ & $\begin{array}{l}-0.147 \\
(0.074)\end{array}$ \\
\hline Panama & $\begin{array}{l}-0.328 \\
(0.168)\end{array}$ & $\begin{array}{l}-0.723^{* *} \\
(0.226)\end{array}$ & $\begin{array}{l}-0.015 \\
(0.071)\end{array}$ \\
\hline $\begin{array}{l}\text { Control parameters: } \\
\text { reported ties on website? }\end{array}$ & $\begin{array}{l}1.257 * * * \\
(0.115)\end{array}$ & $\begin{array}{l}1.431 * * * \\
(0.082)\end{array}$ & $\begin{array}{l}1.439 * * * \\
(0.054)\end{array}$ \\
\hline density & $\begin{array}{l}-8.856^{* * *} \\
(0.547)\end{array}$ & $\begin{array}{l}-5.750^{* * *} \\
(0.134)\end{array}$ & $\begin{array}{l}-7.017 * * * \\
(0.102)\end{array}$ \\
\hline isolates & $\begin{array}{l}-4.199 * * * \\
(0.862)\end{array}$ & $\begin{array}{l}-0.155 \\
(0.919)\end{array}$ & \\
\hline
\end{tabular}

building ties to other regional actors. This is analogous to the type of "rewiring" process seen in small-world networks, which preserves local clustering while reducing average path length.

From a methodological standpoint, organizations that do no report partners may have unobserved ties. If the nonreporting organizations have a large number of unobserved ties, the networks here would become denser and decentralized with less variance in the degree distributions. However, to the extent the reporting of ties is positively correlated with the fully observed degree distribution, then the networks are likely to have a qualitatively similar variance in degree distribution to our partially observed data. We think it is likely that organizations with more partners are more likely to report ties, as doing so is consistent with their collaborative strategies, but validating this assumption requires a more completely observed network.

\section{DISCUSSION}

The descriptive statistics and ERGMs largely support our hypothesis that multilevel water governance networks possess structural properties that resemble small-world networks. The local network is characterized by closed structures occurring within country-level subgroups and coordinated by central incountry actors, which provides a basis for cooperation and on- the-ground project implementation. The regional network is characterized by relatively more open structures, and provides more horizontal boundary-spanning ties between Central American countries, which help facilitate social learning and resource distribution across the region. When all ties are taken into account in the multilevel network, regional organizations provide the largest number of cross-level, vertical relationships to local actors. These cross-level ties shorten the average path length among the entire set of local and regional actors without degrading general patterns of localized clustering, and result in the small-world structure of the multilevel network.

The policy implications of small-world structures suggest both opportunities and constraints in the regional water governance network in Central America. On the one hand, we find evidence that regional actors can help bridge between distant local-level actors, thereby helping foster cooperation and knowledge and resource sharing across local political boundaries throughout the region. However, the overarching importance of regional actors also potentially makes the network vulnerable to the "exit problem" when funding and project cycles come to a close and regional actors and their resources disappear from the network. In this regard, the sustainability of relations over time is key, and regional policy actors that are not permanent fixtures on the 
institutional landscape should make relationship building a core aim of their exit strategies (Hileman et al. 2018). Furthermore, there is also a risk that regional actors in the core of the network may pursue policy goals that are contrary to collective regional benefits, due to lack of capacity or substitution of international preferences. This highlights the need for additional theory and empirical analysis to explore the relationship between political power, cooperation, and learning (Morrison et al. 2017).

We also find evidence for homophily at the local and regional levels, which is associated with closed structures that may facilitate cooperation. However, the continued presence of homophily can also serve as a barrier to learning across boundaries, or facilitate intergroup conflict as seen in the broad literature on international environmental agreements (Young 1999, Keohane 2002) and advocacy coalitions in policy systems (Sabatier 1988, Sabatier and Jenkins-Smith 1993). These findings suggest that both local and regional actors are constrained by context, in spite of regional actors frequently having increased access to knowledge and material resources. Regional actors that seek to maintain a politically neutral profile while also creating cross-level ties may be particularly hesitant to address these core social and political issues.

Furthermore, while the multilevel water governance network for Central America possesses small-world structures that can simultaneously facilitate cooperation, social learning, and resource distribution, the fact remains that serious challenges to water resource development and management persist in the region. Network structures ultimately represent the potential for facilitating different governance processes, and underlying social and political issues such as power asymmetries and low levels of social capital may hinder the benefits these structures can provide (Henry and Vollan 2014, Morrison et al. 2017). In practice, development programs may prioritize building social capital and trust among local actors, and facilitating interactions and exchanges among diverse regional actors in order to access the benefits of these network structures. As interest in regional governance continues to grow, it remains critically important to tailor strategies to the unique needs and circumstances facing localities throughout the seven countries in Central America. That regional governance is not a panacea is not surprising, and is further reinforced in the ERGM results which demonstrate that beyond the strong homophily effect, there is variation in the baseline activity of actors within each of the countries.

A high-level goal of this paper was to bring a formal network model, small-world networks, to an empirical context and assess the utility of the approach. While the analysis sheds light on a number of interesting findings presented here, future studies should expand on this research agenda by examining different forms of collaboration, and additional social and ecological variables. There remains a pressing need for empirical studies that link network structures to biophysical and socio-political outcomes, and our hypothesis regarding the benefits of smallworld networks cannot be fully tested without data on outcomes that quantify the performance of small-world networks in comparison to other network typologies. To assess the prevalence of small-world networks in different settings, it is also critical to compare network topologies across a range of social-ecological contexts. Lastly, governance networks are constantly evolving, and we recognize the network examined here is a cross-section. Combining panel series network and outcomes data from many different social-ecological systems should be a core goal of future research on multilevel governance. Our ability to connect the evolution of networks and their associated social processes to outcomes also depends on research designs that can more fully observe and measure networks, along with continued advancement of statistical methods that are capable of making inferences about network structures and processes in the presence of unobserved links.

\section{CONCLUSIONS}

Our analysis highlights the utility of applying the idea of smallworld networks to analyze the structure of a multilevel water governance network in Central America. Small-world networks are consistent with the requirement of polycentric governance systems to facilitate cooperation, social learning, and resource distribution. This suggests that the evolution of regional water governance in Central America may be a positive response to emerging interdependencies from global processes. However, our analysis is limited in time and space; more comparative work is needed to understand how networks evolve over time in different social-ecological contexts, including the role of macrolevel domestic and international political institutions. Such analyses must ultimately connect the structure of governance networks and polycentric institutions to environmental outcomes and institutional resilience in the face of change. Furthermore, we are not prepared to claim that small-world networks are a panacea for analyzing governance networks. Rather, they provide a parsimonious and simple theoretical framework that connects to complicated ideas around cooperation, learning, and other social processes in governance. Other simple theoretical models may also be useful, or it may be that polycentric systems are too complex to be amenable to any of the existing approaches in network science.

\section{Responses to this article can be read online at: http://www.ecologyandsociety.org/issues/responses. $\mathrm{php} / 10282$}

\section{Acknowledgments:}

Early versions of this paper were previously presented at the 2015 Political Networks conference, and the 2016 Sunbelt Social Networks conference. The authors would like to thank Manuel Fischer, Matthew Hamilton, Lorien Jasny, Philip Leifeld, Michael Levy, the Center for Environmental Policy and Behavior at UC Davis, and their anonymous reviewers for all the helpful comments and critiques provided during the course of this research project.

\section{LITERATURE CITED}

Adger, W. N., K. Brown, and E. L. Tompkins. 2005a. The political economy of cross-scale networks in resource co-management. Ecology and Society 10(2):9. http://dx.doi.org/10.5751/ES-01465-100209

Adger, W. N., T. P. Hughes, C. Folke, S. R. Carpenter, and J. Rockström. 2005b. Social-ecological resilience to coastal disasters. Science 309(5737):1036-1039. http://dx.doi.org/10.1126/ 


\section{$\underline{\text { science. } 1112122}$}

Anderies, J. M., M. A. Janssen, and E. Ostrom. 2004. A framework to analyze the robustness of social-ecological systems from an institutional perspective. Ecology and Society 9(1):18. http://dx. doi.org/10.5751/ES-00610-090118

Barabási, A.-L., and R. Albert. 1999. Emergence of scaling in random networks. Science 286(5439):509-512. http://dx.doi. org/10.1126/science.286.5439.509

Barrett, C. B., K. Brandon, C. Gibson, and H. Gjertsen. 2001. Conserving tropical biodiversity amid weak institutions. BioScience 51(6):497-502. http://dx.doi.org/10.1641/0006-3568 (2001)051[0497:CTBAWI]2.0.CO;2

Berardo, R., and M. Lubell. 2016. Understanding what shapes a polycentric governance system. Public Administration Review 76 (5):738-751. http://dx.doi.org/10.1111/puar.12532

Berardo, R., and J. T. Scholz. 2010. Self-organizing policy networks: risk, partner selection, and cooperation in estuaries. American Journal of Political Science 54(3):632-649. http://dx.doi. org/10.1111/j.1540-5907.2010.00451.x

Berkes, F. 2004. Rethinking community-based conservation. Conservation Biology 18(3):621-630. http://dx.doi.org/10.1111/ j.1523-1739.2004.00077.x

Berkes, F. 2007. Community-based conservation in a globalized world. Proceedings of the National Academy of Sciences of the United States of America 104(39):15188-15193. http://dx.doi. org/10.1073/pnas.0702098104

Berkes, F., and N. J. Turner. 2006. Knowledge, learning and the evolution of conservation practice for social-ecological system resilience. Human Ecology 34(4):479-494. http://dx.doi. org/10.1007/s10745-006-9008-2

Bodin, Ö. 2017. Collaborative environmental governance: achieving collective action in social-ecological systems. Science 357(6352):eaan1114. http://dx.doi.org/10.1126/science.aan1114

Bodin, Ö., and B. I. Crona. 2009. The role of social networks in natural resource governance: What relational patterns make a difference? Global Environmental Change 19(3):366-374. http:// dx.doi.org/10.1016/j.gloenvcha.2009.05.002

Bodin, Ö., B. Crona, and H. Ernstson. 2006. Social networks in natural resource management: What is there to learn from a structural perspective? Ecology and Society 11(2):r2. http://dx. doi.org/10.5751/ES-01808-1102r02

Bodin, Ö., B. Crona, M. Thyresson, A.-L. Golz, and M. Tengö. 2014. Conservation success as a function of good alignment of social and ecological structures and processes. Conservation Biology 28(5):1371-1379. http://dx.doi.org/10.1111/cobi.12306

Bodin, Ö., G. Robins, R. R. J. McAllister, A. M. Guerrero, B. Crona, M. Tengö, and M. Lubell. 2016. Theorizing benefits and constraints in collaborative environmental governance: a transdisciplinary social-ecological network approach for empirical investigations. Ecology and Society 21(1):40. http://dx. doi.org/10.5751/ES-08368-210140

Borgatti, S. P., and M. G. Everett. 2000. Models of core/periphery structures. Social Networks 21(4):375-395. http://dx.doi.
org/10.1016/S0378-8733(99)00019-2

Butts, C. T. 2008. Social network analysis with sna. Journal of Statistical Software 24(6):1-51. http://dx.doi.org/10.18637/jss. $\underline{\mathrm{v} 024 . \mathrm{i} 06}$

Carlsson, L. G., and A. C. Sandström. 2007. Network governance of the commons. International Journal of the Commons 2 (1):33-54. http://dx.doi.org/10.18352/ijc.20

Cash, D. W., W. N. Adger, F. Berkes, P. Garden, L. Lebel, P. Olsson, L. Pritchard, and O. Young. 2006. Scale and cross-scale dynamics: governance and information in a multilevel world. Ecology and Society 11(2):8. http://dx.doi.org/10.5751/ES-01759-110208

Csárdi, G., and T. Nepusz. 2006. The igraph software package for complex network research. InterJournal, Complex Systems 1695 (5):1-9.

Davis, G. F., M. Yoo, and W. E. Baker. 2003. The small world of the American corporate elite, 1982-2001. Strategic Organization 1(3):301-326. http://dx.doi.org/10.1177/14761270030013002

Davis, S., P. Hicks, and A. Pocasangre. 2014. Six factors for improving rural water services in Central America. Global Water Initiative.

Dodman, D., and D. Mitlin. 2013. Challenges for communitybased adaptation: discovering the potential for transformation. Journal of International Development 25(5):640-659. http://dx. doi.org/10.1002/jid.1772

Duxbury, S. W. 2018. Diagnosing multicollinearity in exponential random graph models. Open Science Framework.

Engle, N. L., and M. C. Lemos. 2010. Unpacking governance: building adaptive capacity to climate change of river basins in Brazil. Global Environmental Change 20(1):4-13. http://dx.doi. org/10.1016/j.gloenvcha.2009.07.001

Folke, C., S. Carpenter, T. Elmqvist, L. Gunderson, C. S. Holling, and B. Walker. 2002. Resilience and sustainable development: building adaptive capacity in a world of transformations. $A M B I O$ 31(5):437-440. http://dx.doi.org/10.1579/0044-7447-31.5.437

Folke, C., T. Hahn, P. Olsson, and J. Norberg. 2005. Adaptive governance of social-ecological systems. Annual Review of Environment and Resources 30(1):441-473. http://dx.doi. org/10.1146/annurev.energy.30.050504.144511

García-López, G. A. 2013. Scaling up from the grassroots and the top down: the impacts of multi-level governance on community forestry in Durango, Mexico. International Journal of the Commons 7(2):406-431. http://dx.doi.org/10.18352/ijc.437

Gibson, C. C., E. Ostrom, and T. K. Ahn. 2000. The concept of scale and the human dimensions of global change: a survey. Ecological Economics 32(2):217-239. http://dx.doi.org/10.1016/ $\underline{\text { S0921-8009(99)00092-0 }}$

Gleick, P. H., and N. Ajami. 2014. The world's water volume 8: the biennial report on freshwater resources. Island Press.

Guerrero, A. M., Ö. Bodin, R. R. J. McAllister, and K. A. Wilson. 2015a. Achieving social-ecological fit through bottom-up collaborative governance: an empirical investigation. Ecology and Society 20(4):41. http://dx.doi.org/10.5751/ES-08035-200441 
Guerrero, A. M., R. R. J. Mcallister, and K. A. Wilson. $2015 b$. Achieving cross-scale collaboration for large scale conservation initiatives. Conservation Letters 8(2):107-117. http://dx.doi. org/10.1111/conl.12112

Gupta, J., and C. Pahl-Wostl. 2013. Global water governance in the context of global and multilevel governance: its need, form, and challenges. Ecology and Society 18(4):53. http://dx.doi. org/10.5751/ES-05952-180453

Hamilton, M., and M. Lubell. 2017. Collaborative governance of climate change adaptation across spatial and institutional scales. Policy Studies Journal 46(2):222-247. http://dx.doi.org/10.1111/ psj. 12224

Handcock, M. S., D. R. Hunter, C. T. Butts, S. M. Goodreau, and M. Morris. 2008. statnet: software tools for the representation, visualization, analysis and simulation of network data. Journal of Statistical Software 24(1):1548-7660. http://dx.doi.org/10.18637/ jiss.v024.i01

Hanneman, R. A., and M. Riddle. 2005. Working with network data. Page introduction to social network methods. University of California, Riverside, Riverside, California, USA.

Henry, A. D. 2017. Network Segregation and Policy Learning. Pages 559-587 in J. N. Victor, A. H. Montgomery, and M. N. Lubell. editors. The Oxford handbook of political networks. Oxford University Press.

Henry, A. D., and B. Vollan. 2014. Networks and the challenge of sustainable development. Annual Review of Environment and Resources 39(1):583-610. http://dx.doi.org/10.1146/annurevenviron-101813-013246

Hileman, J., M. T. A. Bastos, and M. Lubell. 2018. Robustness and the paradox of bridging organizations: the exit problem in regional water governance networks in Central America. Society \& Natural Resources 31(6):683-697. http://dx.doi. org/10.1080/08941920.2017.1423436

Hileman, J., P. Hicks, and R. Jones. 2016. An alternative framework for analysing and managing conflicts in integrated water resources management (IWRM): linking theory and practice. International Journal of Water Resources Development 32(5):675-691. http://dx.doi.org/10.1080/07900627.2015.1076719

Hunter, D. R. 2007. Curved exponential family models for social networks. Social Networks 29(2):216-230. http://dx.doi. org/10.1016/j.socnet.2006.08.005

Ika, L. A., and J. Donnelly. 2017. Success conditions for international development capacity building projects. International Journal of Project Management 35(1):44-63. http://dx.doi. org/10.1016/j.ijproman.2016.10.005

Jackson, M. O. 2008. Social and economic networks. Princeton University Press, Princeton, New Jersey, USA.

Janssen, M. A., Ö. Bodin, J. M. Anderies, T. Elmqvist, H. Ernstson, R. R. J. McAllister, P. Olsson, and P. Ryan. 2006. Toward a network perspective of the study of resilience in socialecological systems. Ecology and Society 11(1):15. http://dx.doi. org/10.5751/ES-01462-110115

Keohane, R. 2002. Power and governance in a partially globalized world. Psychology Press.

Kuzdas, C., and A. Wiek. 2014. Governance scenarios for addressing water conflicts and climate change impacts. Environmental Science \& Policy 42:181-196. http://dx.doi. org/10.1016/j.envsci.2014.06.007

Lebel, L., J. M. Anderies, B. Campbell, C. Folke, S. HatfieldDodds, T. P. Hughes, and J. Wilson. 2006. Governance and the capacity to manage resilience in regional social-ecological systems. Ecology and Society 11(1):19. http://dx.doi.org/10.5751/ ES-01606-110119

Lemos, M. C., and A. Agrawal. 2006. Environmental governance. Annual Review of Environment and Resources 31(1):297-325. http://dx.doi.org/10.1146/annurev.energy.31.042605.135621

Levy, M. A., and M. N. Lubell. 2017. Innovation, cooperation, and the structure of three regional sustainable agriculture networks in California. Regional Environmental Change 18 (4):1235-1246. http://dx.doi.org/10.1007/s10113-017-1258-6

Lomi, A., G. Robins, and M. Tranmer. 2016. Introduction to multilevel social networks. Social Networks 44:266-268. http://dx. doi.org/10.1016/j.socnet.2015.10.006

Lubell, M. 2013. Governing institutional complexity: the ecology of games framework. Policy Studies Journal 41(3):537-559. http:// dx.doi.org/10.1111/psj.12028

Lubell, M., G. Robins, and P. Wang. 2014. Network structure and institutional complexity in an ecology of water management games. Ecology and Society 19(4):23. http://dx.doi.org/10.5751/ ES-06880-190423

Lubell, M., J. Scholz, R. Berardo, and G. Robins. 2012. Testing policy theory with statistical models of networks. Policy Studies Journal 40(3):351-374. http://dx.doi.org/10.1111/j.1541-0072.2012.00457. $\underline{x}$

Mani, D., and J. Moody. 2014. Moving beyond stylized economic network models: the hybrid world of the Indian firm ownership network. American Journal of Sociology 119(6):1629-1669. http:// dx.doi.org/10.1086/676040

McAllister, R. R. J., C. J. Robinson, A. Brown, K. Maclean, S. Perry, and S. Liu. 2017. Balancing collaboration with coordination: contesting eradication in the Australian plant pest and disease biosecurity system. International Journal of the Commons 11(1):330-354. http://dx.doi.org/10.18352/ijc.701

McAllister, R. R. J., C. J. Robinson, K. Maclean, A. M. Guerrero, K. Collins, B. M. Taylor, and P. J. De Barro. 2015. From local to central: a network analysis of who manages plant pest and disease outbreaks across scales. Ecology and Society 20(1):67. http://dx. doi.org/10.5751/ES-07469-200167

Milgram, S. 1967. The small world problem. Psychology Today 2 (1):60-67.

Mohan, G., and K. Stokke. 2000. Participatory development and empowerment: the dangers of localism. Third World Quarterly 21 (2):247-268. http://dx.doi.org/10.1080/01436590050004346

Morrison, T. H., W. N. Adger, K. Brown, M. C. Lemos, D. Huitema, and T. P. Hughes. 2017. Mitigation and adaptation in polycentric systems: sources of power in the pursuit of collective 
goals. WIRES Climate Change 8(5):e479. http://dx.doi. org/10.1002/wcc.479

Nelson, F. 2009. Conservation and aid: designing more effective investments in natural resource governance reform. Conservation Biology 23(5):1102-1108. http://dx.doi.org/10.1111/j.1523-1739.2009.01195. $\underline{\mathrm{x}}$

Newman, M., A.-L. Barabási, and D. J. Watts. 2006. The structure and dynamics of networks. Princeton University Press, Princeton, New Jersey, USA. http://dx.doi.org/10.1515/9781400841356

Newman, M. E. J., and D. J. Watts. 1999. Renormalization group analysis of the small-world network model. Physics Letters A 263 (4-6):341-346. http://dx.doi.org/10.1016/S0375-9601(99)00757-4

Olsson, P., C. Folke, and F. Berkes. 2004. Adaptive comanagement for building resilience in social-ecological systems. Environmental Management 34(1):75-90. http://dx.doi.org/10.1007/s00267-003-0101-7

Olsson, P., L. H. Gunderson, S. R. Carpenter, P. Ryan, L. Lebel, C. Folke, and C. S. Holling. 2006. Shooting the rapids: navigating transitions to adaptive governance of social-ecological systems. Ecology and Society 11(1):18. http://dx.doi.org/10.5751/ ES-01595-110118

Ostrom, E. 1990. Governing the commons: the evolution of institutions for collective action. Cambridge University Press.

Ostrom, E. 2009. A general framework for analyzing sustainability of social-ecological systems. Science 325 (5939):419-422. http://dx.doi.org/10.1126/science.1172133

Pahl-Wostl, C. 2015. Multi-level and cross-scale governance. Pages 99-124 in Water governance in the face of global change: from understanding to transformation. Springer International Publishing. http://dx.doi.org/10.1007/978-3-319-21855-7 6

Pahl-Wostl, C., M. Craps, A. Dewulf, E. Mostert, D. Tabara, and T. Taillieu. 2007. Social learning and water resources management. Ecology and Society 12(2):5. http://dx.doi. org/10.5751/ES-02037-120205

Pahl-Wostl, C., J. Gupta, and D. Petry. 2008. Governance and the global water system: a theoretical exploration. Global Governance 14(4):419-435.

Pietri, D. M., T. C. Stevenson, and P. Christie. 2015. The Coral Triangle Initiative and regional exchanges: strengthening capacity through a regional learning network. Global Environmental Change 33:165-176. http://dx.doi.org/10.1016/j.gloenvcha.2015.05.005

Pretty, J., and H. Ward. 2001. Social capital and the environment. World Development 29(2):209-227. http://dx.doi.org/10.1016/ $\underline{\mathrm{S} 0305-750 \mathrm{X}(00) 00098-\mathrm{X}}$

R Development Core Team. 2016. R: a language and environment for statistical computing. CRAN, Vienna, Austria.

Robinson, L. W., and F. Berkes. 2011. Multi-level participation for building adaptive capacity: formal agency-community interactions in northern Kenya. Global Environmental Change 21 (4):1185-1194. http://dx.doi.org/10.1016/j.gloenvcha.2011.07.012

Sabatier, P. A. 1988. An advocacy coalition framework of policy change and the role of policy-oriented learning therein. Policy Sciences 21(2-3):129-168. http://dx.doi.org/10.1007/BF00136406
Sabatier, P., and H. Jenkins-Smith. 1993. Policy change and learning: an advocacy coalition approach. Westview Press, Boulder, Colorado, USA.

Sandström, A., and L. Carlsson. 2008. The performance of policy networks: the relation between network structure and network performance. Policy Studies Journal 36(4):497-524. http://dx.doi. org/10.1111/j.1541-0072.2008.00281.x

Taylor, R. G., B. Scanlon, P. Döll, M. Rodell, R. van Beek, Y. Wada, L. Longuevergne, M. Leblanc, J. S. Famiglietti, M. Edmunds, L. Konikow, T. R. Green, J. Chen, M. Taniguchi, M. F. P. Bierkens, A. MacDonald, Y. Fan, R. M. Maxwell, Y. Yechieli, J. J. Gurdak, D. M. Allen, M. Shamsudduha, K. Hiscock, P. J.-F. Yeh, I. Holman, and H. Treidel. 2013. Ground water and climate change. Nature Climate Change 3(4):322-329. http://dx.doi. org/10.1038/nclimate1744

Uzzi, B., L. A. Amaral, and F. Reed-Tsochas. 2007. Small-world networks and management science research: a review. European Management Review 4(2):77-91. http://dx.doi.org/10.1057/ palgrave.emr. 1500078

Uzzi, B., and J. Spiro. 2005. Collaboration and creativity: the small world problem. American Journal of Sociology 111(2):447-504. http://dx.doi.org/10.1086/432782

Vörösmarty, C. J., P. Green, J. Salisbury, and R. B. Lammers. 2000. Global water resources: vulnerability from climate change and population growth. Science 289(5477):284-288. http://dx.doi. org/10.1126/science.289.5477.284

Wang, P., G. Robins, P. Pattison, and E. Lazega. 2013. Exponential random graph models for multilevel networks. Social Networks 35(1):96-115. http://dx.doi.org/10.1016/j.socnet.2013.01.004

Wasserman, S., and K. Faust. 1994. Social network analysis: methods and applications. Cambridge University Press.

Watts, D. J. 1999. Networks, dynamics, and the small-world phenomenon. American Journal of Sociology 105(2):493-527. http://dx.doi.org/10.1086/210318

Watts, D. J., and S. H. Strogatz. 1998. Collective dynamics of 'small-world' networks. Nature 393(6684):440-442. http://dx. doi. org/10.1038/30918

Wyborn, C., and R. P. Bixler. 2013. Collaboration and nested environmental governance: scale dependency, scale framing, and cross-scale interactions in collaborative conservation. Journal of Environmental Management 123:58-67. http://dx.doi.org/10.1016/ j.jenvman.2013.03.014

Yi, H., and J. T. Scholz. 2016. Policy networks in complex governance subsystems: observing and comparing hyperlink, media, and partnership networks. Policy Studies Journal 44 (3):248-279. http://dx.doi.org/10.1111/psj.12141

Young, O. 1999. The effectiveness of international environmental regimes: causal connections and behavioral mechanisms. MIT Press.

Young, O. 2006. Vertical interplay among scale-dependent environmental and resource regimes. Ecology and Society 11 (1):27. http://dx.doi.org/10.5751/ES-01519-110127 


\section{Appendix 1}

Supplemental Descriptive Statistics and ERGM Results

Table A1.1: Descriptive statistics illustrating the effects of removing pendants on the structure of the local, regional, and multi-level networks

\begin{tabular}{|c|c|c|c|c|c|c|}
\hline $\begin{array}{l}\text { Descriptive } \\
\text { statistic }\end{array}$ & $\begin{array}{l}\text { Local } \\
\text { network } \\
\text { (pendants) }\end{array}$ & $\begin{array}{l}\text { Local } \\
\text { network (no } \\
\text { pendants) }\end{array}$ & $\begin{array}{l}\text { Regional } \\
\text { network } \\
\text { (pendants) }\end{array}$ & $\begin{array}{l}\text { Regional } \\
\text { network (no } \\
\text { pendants) }\end{array}$ & $\begin{array}{l}\text { Multi-level } \\
\text { network } \\
\text { (pendants) }\end{array}$ & $\begin{array}{l}\text { Multi-level } \\
\text { network (no } \\
\text { pendants) }\end{array}$ \\
\hline Nodes & 741 & 320 & 1286 & 304 & 2027 & 624 \\
\hline Density & 0.003 & 0.010 & 0.002 & 0.016 & 0.003 & 0.009 \\
\hline $\begin{array}{l}\text { Average } \\
\text { degree }\end{array}$ & 2.5 & 3.2 & 2.7 & 4.8 & 3.1 & 5.6 \\
\hline $\begin{array}{l}\text { Degree } \\
\text { centralization }\end{array}$ & 0.091 & 0.097 & 0.136 & 0.217 & 0.187 & 0.142 \\
\hline $\begin{array}{l}\text { Average local } \\
\text { clustering } \\
\text { coefficient }\end{array}$ & 0.090 & 0.227 & 0.039 & 0.173 & 0.054 & 0.188 \\
\hline $\begin{array}{l}\text { Average path } \\
\text { length }\end{array}$ & 8.19 & 8.09 & 4.38 & 3.51 & 4.33 & 3.58 \\
\hline $\begin{array}{l}\text { Small-world } \\
\text { quotient }\end{array}$ & 22.86 & 13.70 & 31.52 & 11.33 & 55.32 & 21.97 \\
\hline
\end{tabular}

The decision to remove pendant nodes prior to analysis has an effect on both the descriptive statistics and ERGMs, and to assess the impacts we examined results for the local, regional, and multi-level networks with and without pendants ${ }^{1}$. Removing pendants from the local, regional, and multi-level networks leads to a uniform increase in density, average degree, and average local clustering coefficient, and a decrease in average path length and the small-world quotient (Table A1.1). In the case of the local and regional networks, removing pendants increases the overall degree centralization, indicating the pendants are more evenly distributed through these networks, as opposed to concentrating on one or more high-degree nodes. However, the removal of pendants in the multi-level network leads to a decrease in degree centralization, which indicates a disproportionate number of pendants providing cross-level ties are connected to a relatively small number of the same high-degree actors in the multilevel network.

Importantly, removing pendants does not fundamentally alter the interpretation of the empirical results. Closed structures are more prevalent in the local network, both with and without pendants, as evidenced by the higher average local clustering coefficient when compared with the regional network. Open structures are more prevalent at the regional level, both with and without pendants, as evidenced by the higher degree centralization when compared with the local network. The multi-level network effectively balances the closed and open structures found at the local and regional levels, respectively, as evidenced by the small-world quotient

\footnotetext{
${ }^{1}$ Given the large number of pendants $(\sim 1,400)$ in the network dataset, we did not code pendants as local or regional actors. Instead, we focus more generally on the structures that arise when pendants are included in both the local and regional networks, effectively treating pendants as a neutral category with respect to the level variable.
} 
being greater, both with and without pendants, when compared to the local and regional networks.

Table A1.2: ERGM results illustrating the effects of removing pendants on the coefficient for anti-preferential attachment, in the absence of any other endogenous or exogenous model terms

\begin{tabular}{|c|c|c|c|c|c|c|}
\hline $\begin{array}{l}\text { ERGM } \\
\text { coefficient }\end{array}$ & $\begin{array}{l}\text { Local } \\
\text { network } \\
\text { (pendants) }\end{array}$ & $\begin{array}{l}\text { Local } \\
\text { network (no } \\
\text { pendants) }\end{array}$ & $\begin{array}{l}\text { Regional } \\
\text { network } \\
\text { (pendants) }\end{array}$ & $\begin{array}{l}\text { Regional } \\
\text { network (no } \\
\text { pendants) }\end{array}$ & $\begin{array}{l}\text { Multi-level } \\
\text { network } \\
\text { (pendants) }\end{array}$ & $\begin{array}{l}\text { Multi-level } \\
\text { network (no } \\
\text { pendants) }\end{array}$ \\
\hline Edges & $\begin{array}{l}-5.410 * * * \\
(0.048)\end{array}$ & $\begin{array}{l}-4.362 * * * \\
(0.058)\end{array}$ & $\begin{array}{l}-5.812 * * * \\
(0.033)\end{array}$ & $\begin{array}{l}-3.950 * * * \\
(0.040)\end{array}$ & $\begin{array}{l}-6.106 * * * \\
(0.022)\end{array}$ & $\begin{array}{l}-4.647 * * * \\
(0.026)\end{array}$ \\
\hline $\begin{array}{l}\text { Anti- } \\
\text { preferential } \\
\text { attachment }^{\dagger}\end{array}$ & $\begin{array}{l}-0.798 * * * \\
(0.117)\end{array}$ & $\begin{array}{l}-1.028^{* * * *} \\
(0.191)\end{array}$ & $\begin{array}{l}-1.157 * * * \\
(0.084)\end{array}$ & $\begin{array}{l}-1.902 * * * \\
(0.210)\end{array}$ & $\begin{array}{l}-1.501 * * * \\
(0.067)\end{array}$ & $\begin{array}{l}-1.317 * * * \\
(0.240)\end{array}$ \\
\hline
\end{tabular}

$* \mathrm{p}<0.1, * * \mathrm{p}<0.05, * * * \mathrm{p}<0.01$

${ }^{\dagger}$ Decay parameter fixed at 0.3

Table A1.2 illustrates how the anti-preferential attachment (geometrically-weighted degree) coefficient in the ERGMs, in the absence of any other endogenous or exogenous model terms, changes when pendants are removed from the local, regional, and multi-level networks. These results further illustrate how geometrically-weighted degree tracks network centralization when it is the sole term included in the ERGMs. In all the networks, both with and without pendants, the anti-preferential attachment coefficient is negative, indicating a propensity for actors to form ties with relatively high-degree actors. In the case of the local and regional networks, degree centralization increases when pendants are removed from the networks (Table A1.1), and this is reflected in the anti-preferential attachment coefficient becoming more negative in the ERGMs for these networks when pendants are removed. The multi-level network becomes less centralized when pendants are removed (Table A1.1), and this change is also mirrored in the anti-preferential attachment coefficient becoming less negative in the ERGM for this network when pendants are removed. Consistent with our hypotheses, the regional and multi-level networks have larger negative coefficients than the local network on the anti-preferential attachment statistics.

Table A1.3: ERGM results illustrating the effects of removing pendants on the coefficient for shared partners, in the absence of any other endogenous or exogenous model terms

\begin{tabular}{lllllll}
$\begin{array}{l}\text { ERGM } \\
\text { coefficient }\end{array}$ & $\begin{array}{l}\text { Local } \\
\text { network } \\
\text { (pendants) }\end{array}$ & $\begin{array}{l}\text { Local } \\
\text { network (no } \\
\text { pendants) }\end{array}$ & $\begin{array}{l}\text { Regional } \\
\text { network } \\
\text { (pendants) }\end{array}$ & $\begin{array}{l}\text { Regional } \\
\text { network (no } \\
\text { pendants) }\end{array}$ & $\begin{array}{l}\text { Multi-level } \\
\text { network } \\
\text { (pendants) }\end{array}$ & $\begin{array}{l}\text { Multi-level } \\
\text { network (no } \\
\text { pendants) }\end{array}$ \\
\hline Edges & $-6.045^{* * *}$ & $-5.364 * * *$ & $-6.425 * * *$ & $-4.765 * * *$ & $-6.838^{* * *}$ & $-5.415^{* * *}$ \\
Shared & $(0.039)$ & $(0.068)$ & $(0.027)$ & $(0.055)$ & $(0.021)$ & $(0.036)$ \\
partners & $1.458^{*} * *$ & $1.471^{*} * *$ & $1.413 * * *$ & $1.024 * * *$ & $1.648 * * *$ & $1.242^{* * *}$ \\
\hline
\end{tabular}

$* \mathrm{p}<0.1, * * \mathrm{p}<0.05, * * * \mathrm{p}<0.01$

†Decay parameter fixed at 0.3 
Table A1.3 illustrates how the shared partners (geometrically-weighted edgewise shared partners) coefficient does not change substantially when pendants are removed from the local, regional, and multi-level networks. The positive coefficients indicate there is a propensity for triadic closure in all the networks, regardless of whether pendants are included or removed.

Table A1.4: Model results illustrating the interplay between within-country homophily and anti-preferential attachment for the local, regional, and multi-level networks. Pendant nodes were not included in any of the networks.

\begin{tabular}{|c|c|c|c|c|c|c|}
\hline $\begin{array}{l}\text { ERGM } \\
\text { coefficient }\end{array}$ & $\begin{array}{l}\text { Local } \\
\text { network } \\
\text { (homophily) }\end{array}$ & $\begin{array}{l}\text { Local } \\
\text { network (no } \\
\text { homophily) }\end{array}$ & $\begin{array}{l}\text { Regional } \\
\text { network } \\
\text { (homophily) }\end{array}$ & $\begin{array}{l}\text { Regional } \\
\text { network (no } \\
\text { homophily) }\end{array}$ & $\begin{array}{l}\text { Multi-level } \\
\text { network } \\
\text { (homophily) }\end{array}$ & $\begin{array}{l}\text { Multi-level } \\
\text { network (no } \\
\text { homophily) }\end{array}$ \\
\hline $\begin{array}{l}\text { Anti- } \\
\text { preferential } \\
\text { attachment }^{\dagger}\end{array}$ & $\begin{array}{l}-2.217^{*} \\
(0.874)\end{array}$ & $\begin{array}{l}2.348 * * * \\
(0.310)\end{array}$ & $\begin{array}{l}1.663 * \\
(0.772)\end{array}$ & $\begin{array}{l}1.617 * * * \\
(0.379)\end{array}$ & $\begin{array}{l}7.535^{* * * *} \\
(0.769)\end{array}$ & $\begin{array}{l}6.584 * * * \\
(0.749)\end{array}$ \\
\hline
\end{tabular}

$* \mathrm{p}<0.1, * * \mathrm{p}<0.05, * * * \mathrm{p}<0.01$

†Decay parameter fixed at 0.3

Table A1.4 illustrates how the positive homophily effect in the ERGMs affects the coefficient for anti-preferential attachment, which has important implications as it relates to network centralization. While only the coefficient for anti-preferential attachment is displayed in the table, the ERGMs include the same suite of endogenous and exogenous variables as the ERGMs presented in the paper, and all other terms were excluded from the table here for ease of interpretation. (Note: the coefficients for anti-preferential attachment in the local, regional, and multi-level networks with homophily are identical to those in Table 2 in the text, as the models are identical.)

In the regional and multi-level ERGMs, the anti-preferential attachment coefficients remain large and positive both with and without homophily. In the local network, the anti-preferential attachment coefficient switches from negative to positive when homophily is not included in the ERGM, which indicates the propensity for actors to form ties with relatively high-degree actors in the local network is occurring among actors working within the same country. It is important to recognize degree centralization is a network-level measure, so while the local network is less centralized overall than the regional or multi-level networks, the force for centralization captured by the negative anti-preferential attachment coefficient is taking place at the sub-network level, and as a direct result of the strong homophily force between local actors from the same country in Central America. In other words, the negative coefficient on gwdegree when homophily is included in the model indicates relatively greater variance in the degree distribution within each country than at the network level, where the exogenous effect of homophily is not considered. 
Table A1.5: Model results illustrating the interdependence between the anti-preferential attachment and "reported partners" variable, in the absence of any other model terms. Pendant nodes were not included in any of the networks.

\begin{tabular}{lllllll}
\hline \hline $\begin{array}{l}\text { ERGM } \\
\text { coefficient }\end{array}$ & $\begin{array}{l}\text { Local } \\
\text { network }\end{array}$ & $\begin{array}{l}\text { Local } \\
\text { network }\end{array}$ & $\begin{array}{l}\text { Regional } \\
\text { network }\end{array}$ & $\begin{array}{l}\text { Regional } \\
\text { network }\end{array}$ & $\begin{array}{l}\text { Multi-level } \\
\text { network }\end{array}$ & $\begin{array}{l}\text { Multi-level } \\
\text { network }\end{array}$ \\
\hline Edges & $-4.362 * * *$ & $-6.604 * * *$ & $-3.950 * * *$ & $-5.399 * * *$ & $-4.647 * * *$ & $-6.345 * * *$ \\
Reported & $(0.058)$ & $(0.190)$ & $(0.040)$ & $\begin{array}{l}(0.104) \\
(0.026)\end{array}$ & $\begin{array}{l}(0.090) \\
1.573 * * *\end{array}$ \\
partners & & $1.685 * * *$ & & $1.554 * * *$ & & --- \\
$\begin{array}{l}\text { Anti- } \\
\text { preferential }\end{array}$ & $-1.028 * * *$ & $1.390 * * *$ & $-1.902 * * *$ & 0.622 & $-1.317 * * *$ & $4.247 * * *$ \\
attachment $^{\dagger}$ & $(0.191)$ & $(0.293)$ & $(0.210)$ & $(0.320)$ & $(0.240)$ & $(0.697)$ \\
\hline
\end{tabular}

$* \mathrm{p}<0.1, * * \mathrm{p}<0.05, * * * \mathrm{p}<0.01$

†'Decay parameter fixed at 0.3

Table A1.5 illustrates the interdependence between the anti-preferential attachment and "reported partners" terms in the ERGMs. Technically, this represents multi-collinearity between the anti-preferential attachment and "reported partners" variables, and understanding the relationship between these two variables is key to interpreting the anti-preferential attachment coefficient in the full ERGMs presented in the paper. When the variable capturing the effect of whether or not actors reported ties on their websites is not included alongside antipreferential attachment, the anti-preferential attachment coefficient decreases, and becomes negative, in each of the local, regional, and multi-level networks. This indicates more network centralization and organization around high-degree nodes, and brings the anti-preferential coefficients in line with the descriptive statistics; the regional network is the most centralized and possesses the most negative anti-preferential attachment coefficient, while the local network is the least centralized and possesses the least negative anti-preferential attachment coefficient.

When the "reported partners" variable is included in the ERGMs alongside anti-preferential attachment, the coefficient on anti-preferential attachment becomes positive in each of the local, regional, and multi-level networks. Interpreted in isolation, a positive anti-preferential attachment coefficient (gwdegree) represents more decentralized networks. However, remembering that gwdegree captures the endogenous variance in the degree distribution, what the anti-preferential attachment coefficient is actually capturing is the low variance part of the degree distribution that is not represented by organizations reporting ties. That is, actors that report ties on their websites have higher average degrees (16.2 and 8.7 when regional and local actors, respectively, report ties, versus 3.5 and 2.8 when they do not), and therefore the inclusion of this exogenous variable in the models captures most of the high-degree nodes in the distribution, and reduces the variance in the degree distribution that is captured by gwdegree. For this reason, in Table A1.4 we see positive anti-preferential attachment coefficients in the regional and multi-level networks, both with and without homophily. 


\section{Appendix 2}

\section{Small-world Quotient Calculation}

Table A2.1: Calculating the small-world quotient for local, regional, and multi-level networks

\begin{tabular}{llllll}
\hline \hline Network & $\begin{array}{l}\text { Observed } \\
\text { average local } \\
\text { clustering } \\
\text { coefficient }\end{array}$ & $\begin{array}{l}\text { Expected } \\
\text { average local } \\
\text { clustering } \\
\text { coefficient }\end{array}$ & $\begin{array}{l}\text { Observed } \\
\text { average path } \\
\text { length }\end{array}$ & $\begin{array}{l}\text { Expected } \\
\text { average path } \\
\text { length }\end{array}$ & $\begin{array}{l}\text { Small-world } \\
\text { quotient }^{\dagger}\end{array}$ \\
\hline Local & 0.227 & 0.010 & 8.09 & 4.93 & 13.70 \\
Regional & 0.173 & 0.016 & 3.51 & 3.64 & 11.33 \\
Multi-level & 0.188 & 0.009 & 3.58 & 3.74 & 21.97 \\
\hline
\end{tabular}

Due to rounding of the variables in the table (for display purposes), performing the calculation using the variables above will result in slight variations from the displayed small-world quotients

Table A2.1 illustrates how the small-world quotient is calculated ${ }^{1}$, and clarifies why the smallworld quotient is largest for the multi-level network. The small-world quotient is obtained by dividing the ratio of observed and expected average local clustering coefficient of a network by the ratio of its observed and expected average path length. The observed values, as the name implies, are the descriptive network statistics obtained from analysis of the empirical network. The expected average local clustering coefficient is calculated by dividing the average degree of a network by the number of nodes in the network, while the expected average path length is calculated by dividing the natural log of the number of nodes by the natural log of the average degree.

Of primary interest here is why the multi-level network possesses the largest small-world quotient, which we hypothesized based on the primary functions of governance, and resulting network structures, we expected would characterize each of the local and regional levels. The relatively large small-world quotient for the multi-level network is partly attributed to the fact the expected clustering is quite low, while the observed clustering remains high; in this scenario, the numerator in the small-world quotient becomes large. At the same time, the expected average path length is low, but not as low as the observed path length; in this scenario, the denominator in the small-world quotient becomes small. The relatively large numerator and small denominator leads to the large small-world quotient in the multi-level network. Stated another way, emphasizing the concepts and not the equation, when cross-level ties are added to the regional and local networks the resulting multi-level network maintains the low average path length observed in the regional network, while the average local clustering coefficient moves toward the high clustering found in the local network. That is, the small-world structure of the multi-level network provides the benefits of both local clustering and regional efficiency.

\footnotetext{
${ }^{1}$ For a full theoretical and methodological explanation, see: Watts, D. J. 1999. Networks, Dynamics, and the Small-World Phenomenon. American Journal of Sociology 105(2):493-527. Another excellent source is Davis, G. F., M. Yoo, and W. E. Baker. 2003. The Small World of the American Corporate Elite, 1982-2001. Strategic Organization 1(3):301-326.
} 


\section{Appendix 3 \\ ERGM Goodness-of-Fit (GOF) Plots}

The following three figures display the results of the goodness-of-fit tests for each of the local, regional, and multi-level network ERGMs. The plots are provided to show the ERGMs converged and were not degenerate, as evidenced by the ability of the models to adequately capture the observed structures in the empirical networks.

Figure A3.1: GOF plots for the local-level ERGM
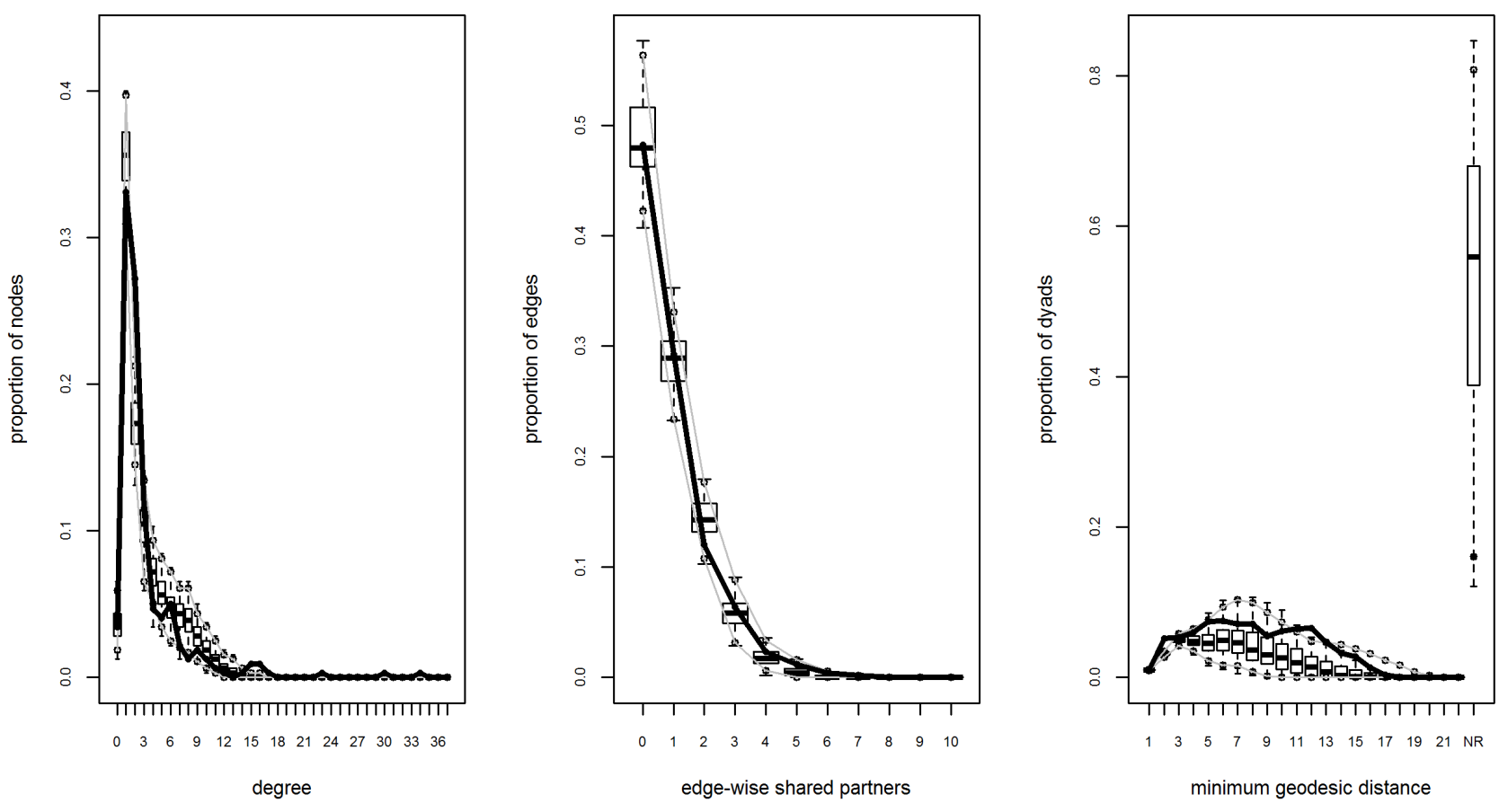
Figure A3.2: GOF plots for the regional-level ERGM


Figure A3.3: GOF plots for the multi-level ERGM
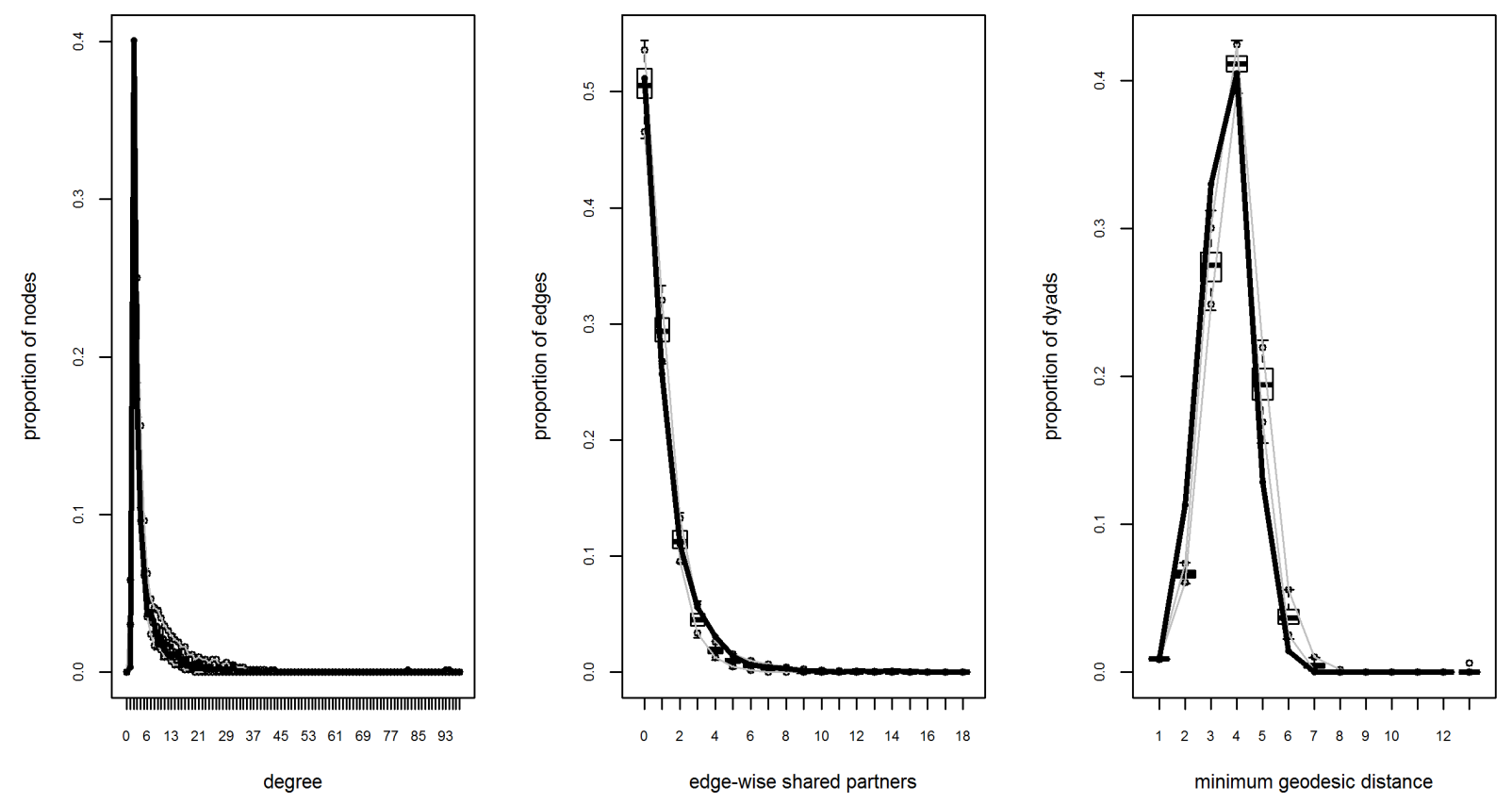


\section{Appendix IV}

Testing for Multicollinearity in ERGMs

Table A4.1: Results from calculating the variance inflation factor (VIF) for the model terms in the local, regional, and multi-level ERGMs

\begin{tabular}{|c|c|c|c|}
\hline $\begin{array}{l}\text { Model variable } \\
\text { (ERGM term) }\end{array}$ & $\begin{array}{l}\text { VIF: Local } \\
\text { ERGM }\end{array}$ & $\begin{array}{l}\text { VIF: Regional } \\
\text { ERGM }\end{array}$ & $\begin{array}{l}\text { VIF: Multi- } \\
\text { level ERGM }\end{array}$ \\
\hline $\begin{array}{l}\text { Shared partners } \\
\text { (gwesp) }\end{array}$ & 6.43 & 5.10 & 5.26 \\
\hline $\begin{array}{l}\text { Anti-preferential } \\
\text { attachment } \\
\text { (gwdegree) }\end{array}$ & 12.89 & 3.39 & 1.28 \\
\hline $\begin{array}{l}\text { Within-level } \\
\text { homophily } \\
\text { (nodematch) }\end{array}$ & -- & -- & 3.11 \\
\hline $\begin{array}{l}\text { Within-country } \\
\text { homophily } \\
\text { (nodematch) }\end{array}$ & 45.59 & 1.26 & 2.47 \\
\hline $\begin{array}{l}\text { Level activity: local } \\
\text { (nodefactor) } \\
\text { Country activity. }\end{array}$ & -- & -- & 6.75 \\
\hline $\begin{array}{l}\text { Country activity: } \\
\text { Costa Rica } \\
\text { (nodefactor) }\end{array}$ & 5.77 & 1.25 & 2.41 \\
\hline $\begin{array}{l}\text { Country activity: } \\
\text { El Salvador } \\
\text { (nodefactor) }\end{array}$ & 8.12 & 1.13 & 2.83 \\
\hline $\begin{array}{l}\text { Country activity: } \\
\text { Guatemala } \\
\text { (nodefactor) }\end{array}$ & 5.85 & 1.07 & 2.16 \\
\hline $\begin{array}{l}\text { Country activity: } \\
\text { Honduras } \\
\text { (nodefactor) }\end{array}$ & 8.08 & 1.03 & 3.12 \\
\hline $\begin{array}{l}\text { Country activity: } \\
\text { Nicaragua } \\
\text { (nodefactor) }\end{array}$ & 4.04 & 1.05 & 1.70 \\
\hline $\begin{array}{l}\text { Country activity: } \\
\text { Panama } \\
\text { (nodefactor) }\end{array}$ & 3.97 & 1.06 & 1.67 \\
\hline $\begin{array}{l}\text { Reported ties on } \\
\text { website? } \\
\text { (nodefactor) }\end{array}$ & 13.03 & 5.70 & 7.69 \\
\hline Isolates & 6.66 & 3.18 & -- \\
\hline
\end{tabular}

We calculated the VIF for each ERGM following the methodology developed by Scott Duxbury, a Ph.D. student at the Ohio State University. The formulation of the "vif-ergm" calculation is publically available on Github, ${ }^{1}$ and is implemented as a function in the R Environment for Statistical Computing. In a paper posted to the Open Science Framework, ${ }^{2}$ 
Mr. Duxbury elaborates on the development of the VIF calculation for ERGMs, and discusses how to interpret the results. He determined any value above 20 is considered to be evidence of potentially problematic collinearity, and any value above 100 is representative of extreme collinearity. In the event of extreme collinearity in an ERGM, even the parameter estimates of terms that do not exhibit a large degree of correlation may be essentially random. We performed the calculation of the VIF for ERGMs exactly as described by Mr. Duxbury, with the only exception being we ran 10,000 simulations instead of using the function's default value of 1,000 simulations.

There is no evidence of extreme collinearity in the three models presented in this paper. Only in one model, specifically the local network ERGM, does a term possess a VIF greater than 20. The VIF score for within-country homophily is 45.6 for the local ERGM, and the presence of two other terms with relatively elevated VIF scores - anti-preferential attachment (12.9) and the "reported ties" variable (13.0) - are correlated with within-country homophily. It is encouraging that further testing, including re-estimating the model, indicated the parameter estimates and standard errors for these three terms were stable and, therefore, multicollinearity in the model may not be highly problematic. However, the presence of even potentially problematic levels of multicollinearity here means the model coefficients must be interpreted with caution, and in this situation it is especially important not to overlook the descriptive statistics assessing open and closed structures.

In the ERGMs for the regional and multi-level networks, all of the VIF scores for the model terms were below 20, indicating low levels of collinearity. In both models the "reported ties" variable displayed the highest VIF score, indicating this variable tends to be the most highly correlated, relatively speaking, with other variables in the model. In the regional model the "reported ties" variable (5.7) is most highly correlated with the shared partners variable (5.1), followed by the anti-preferential attachment variable (3.4). Again, this is due to the fact that actors contributing ties to the network are also more likely to be partners, and to have more partners. In the multi-level model the "reported ties" variable (7.7) is most highly correlated with the "level activity" of local actors (6.8), followed by the shared partners variable (5.3). Similar to the regional model, this is due to the fact that actors contributing ties to the network are more likely to be partners, and less likely to be local actors (who were less likely to have organizational websites and/or report collaborative ties with other actors). However, in the multi-level model there is little to no correlation between anti-preferential attachment and the "reported ties" variable.

While these overall results suggest multicollinearity is not a huge problem given the rule of thumb proposed by Mr. Duxbury, there are coefficients that rank higher than others in terms of VIF. Given this does potentially pose a problem, caution is warranted when interpreting the ERGM coefficients, especially for the suspect variables.

\footnotetext{
${ }^{1}$ Duxbury, S. 2018. R Function to Detect Multicollinearity in ERGM. https://github.com/sduxbury/vif-ergm

${ }^{2}$ Duxbury, S. 2018. Diagnosing Multicollinearity in Exponential Random Graph Models. Forthcoming in Sociological Methods and Research. https://osf.io/yqdxh/
} 